\title{
Offbeat Reference Requests: When to Say Yes and How to Say No
}

\author{
Jessica Petrey \\ Missouri State University
}

\begin{abstract}
This essay explores the more unusual requests faculty and students make that are outside the normal scope of reference services. The author provides a list of considerations deciding to fulfill those requests and suggestions for refusing them.
\end{abstract}

Keywords: Reference services, user research needs

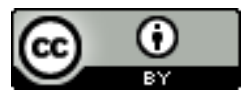

This is an Open Access article distributed under the terms of the Creative Commons Attribution 4.0 International License (http://creativecommons.org/licenses/by/4.0), which permits unrestricted use, distribution, and reproduction in any medium, provided the original work is properly cited. 
Librarianship is changing, and probably always will be. This constant flux, coupled with substantial variety of position types within the field and a healthy dose of stereotypes and assumptions, means that our users rarely fully grasp just what it is that we do. Maybe they are surprised that we offer a certain service, such as manuscript support, or they are disappointed that we need to contact a different librarian to fulfill a simple Inter-Library loan request. Even other librarians may not be familiar with the emerging titles and their associated services, and if other professionals in our field do not know what, say, a Clinical Librarian or Emerging Technologies Librarian does exactly, we must be understanding when users outside of our field have questions. Patrons will make requests for services that do not fall under our normal responsibilities, which can be particularly stressful as a new librarian who is not only still figuring out our role in our organization, but also experiencing a desire to make a good impression with both patrons and colleagues. So what happens when new librarians receive requests for these services we do not technically offer, and how do we balance those unusual requests with user satisfaction and our regular responsibilities? More pointedly, how do we, as new librarians, balance the need for faculty, board, or otherwise powerful patron approval with the occasional need to deny their requests?

Consider the following situations:

1. A graduate student would like you to plot the data from their research into graphs and format the tables for a paper, which they hope to submit tomorrow.

2. A department chair will be an invited speaker at another institution in a few months, and would like to be extra prepared for speaking with the high-ranking faculty she may meet at that institution. The chair would like you to see what you can find out about the research interests, publications, and funding awards of the faculty at the institution she will be visiting.

If neither of these requests are outlined in our job description, we will need to consider the time we have available, our own expertise, the patron that is asking, and the precedent we may set before giving them an answer. 
Time: The first request is not likely to be completed before the deadline, even if it did fall into your job description, so it is simple to politely decline based on the time constraint alone. The second request will probably take longer, but you also have months of warning, and can work on it as it fits into your schedule. Do not only consider how much time you have available to work on this request and whether or not you will be able to complete the project by a given deadline, but also consider the time it will take in proportion to your other duties. Ensure that these bonus requests or services, should you choose to fulfil them, do not consume more of your time than those spelled out within your job description or work plan.

Expertise: There are some things you won't know how to do, and that's okay. You can probably look up those faculty profiles on the institution website and find sufficient information for Request 2, but you might need to brush up on several skills before even attempting to assist the patron in Request 1 . It is better to connect patrons with someone who can give them the best assistance possible, than risk fulfilling their request incorrectly. Consider also that even if you do feel competent in your ability to fulfill a request, there may be someone at your institution who is more competent, or who does have this service in their job description; if that is the case, you should pass the request on to them. Oversimplifying, our job as librarians is essentially to connect people with information. Sometimes we don't have the knowledge to perform a request for them, but we can still give them the information that will connect them with someone who can, or empower them to do it themselves.

Patron: In the first request, the patron is a student. While that does not make them any less important of a patron, it does let us know that they are in a position of learning and their request is likely part of an assignment. Consider whether fulfilling their request will aid them in that 
learning, or simply be completing part of the assignment for them. In this case, it would be better to connect them with resources, such as sending a link to the instructions on table formatting in the word processor they are using, so they can ethically present the work as their own when turning in the assignment. If this had been a traditional literature search request, we would have given the student instruction with database selection and searching, but still would not have completed it for them. In the second request, however, the patron is a department chair who is requesting information for their own knowledge, so there is no conflict of academic dishonesty in assisting them.

Precedent: Assuming you do have the time and skill to complete this request at this time, and have ruled out any ethical conflicts with its completion, how comfortable are you with the precedent it might set? If you accept the request, the patron may ask again. If you accept the request and the patron is impressed with your results, word may spread about this new service you offer and more people may be making the same request. Patrons may even begin assuming this is a service all librarians offer, and begin making requests of your colleagues. If you are comfortable plotting graphs and have time to do so for this patron, for instance, consider whether you are willing to create graphs for all students in that class the next time a similar assignment comes around. The second request, however, is specific enough that-absent any advertising of this kind of research as a service you offer-it is not likely to come up so often as to create problems.

Of course, clear communication of your role and having detailed policies, work plans, or otherwise definitive outlines of your responsibilities will help manage expectations in advance. In this sense, 
being a new librarian is to your advantage; you are a new person, perhaps in a new role, and you have the opportunity to create new or more effectively enforce existing boundaries around that role. However, a user will eventually ask you to do something that you had not planned for in your job description, and you will have to use your own discretion to answer them. The choices you make regarding these unexpected requests can affect your time management, future workload, and user satisfaction, so they must be made carefully. Even when you must deny a request, your patron still will need assistance in some form; to retain goodwill, after denying a request, be proactive in connecting them with someone else who can meet that need, or provide them with resources to help them complete the project themselves. Essentially, returning to our original question, the simplest answer to managing these unanticipated, offbeat requests is to say yes when you can, and provide tools, suggestions, directional assistance, or other options for help when you cannot. 